\title{
Etiology of hemolysis in two patients with hepatitis A infection: glucose-6-phosphate dehydrogenase deficiency or autoimmune hemolytic anemia
}

\author{
Ferda Ozbay Hosnut • Figen Ozcay • \\ Umut Selda Bayrakci • Zekai Avci • Namık Özbek
}

Received: 7 January 2008/Accepted: 11 February 2008 / Published online: 5 March 2008

(C) Springer-Verlag 2008

\begin{abstract}
We report two children with hemolytic anemia during the course of hepatitis A infection. On admission, the patients had high blood urea nitrogen, creatinine, and uric acid levels, as well as anemia, leucocytosis, and direct and indirect hyperbilirubinemia. Both patients had a glucose-6-phosphate dehydrogenase deficiency (G6PD) and autoimmune antibodies. They were given vitamin $\mathrm{K}$ on admission. Inadvertent administration of vitamin $\mathrm{K}$ could have been related to an acute reduction in hemoglobin concentration. To prevent renal damage, plasmapheresis
\end{abstract}

F. Ozbay Hosnut

Fellow of Pediatric Gastroenterology, Hepatology and Nutrition,

Başkent University Faculty of Medicine,

Ankara, Turkey

F. Ozcay

Pediatric Gastroenterology, Hepatology and Nutrition,

Başkent University Faculty of Medicine,

Ankara, Turkey

U. Selda Bayrakci

Department of Pediatric Nephrology,

Başkent University Faculty of Medicine,

Ankara, Turkey

Z. Avci

Fellow of Pediatric Hematology,

Başkent University Faculty of Medicine,

Ankara, Turkey

N. Özbek

Pediatric Hematology, Başkent University Faculty of Medicine,

Ankara, Turkey

F. Ozbay Hosnut $(\bowtie)$

Karapinar Mahallesi Cevizlidere Cad., 68. Sok. No: 6/16, 06460 Dikmen/Ankara, Turkey

e-mail: ferdaozbay72@yahoo.com with fresh frozen plasma was done to clear bilirubin and plasma hemoglobin. The hyperbilirubinemia responded to plasmapheresis. However, acute tubular necrosis complicated the clinical course in one patient, and several sessions of hemodialysis were required. In conclusion, intravascular hemolysis should be considered in patients with hepatitis A infection, marked hyperbilirubinemia, and anemia. Although hepatitis A vaccination is not yet recommended for routine administration, high-risk patients, including those with a G6PD deficiency, should be vaccinated against hepatitis A.

Keywords Glucose-6-phosphate dehydrogenase deficiency (G6PD) - Hepatitis A · Acute renal failure - Hemolysis .

Plasmapheresis · Treatment

\begin{tabular}{ll}
\multicolumn{2}{l}{ Abbreviations } \\
ANA & Antinuclear antibody \\
antidsDNA & Antidouble-stranded deoxyribonucleic acid \\
BUN & Blood urea nitrogen \\
Cr & Creatinine \\
G6PD & Glucose-6-phosphate dehydrogenase deficiency \\
Hb & Hemoglobin \\
LDH & Lactate dehydrogenase \\
SMA & Smooth muscle antibody \\
WBC & White blood cell
\end{tabular}

\section{Introduction}

A variety of extrahepatic manifestations (e.g., acalculous cholecystitis, acute pancreatitis, glomerulonephritis, pleural or pericardial effusion, acute reactive arthritis, neurologic disorders, and hemolytic anemia) can be observed in 
patients with acute hepatitis $\mathrm{A}$ infection. The pathogenic mechanism of hemolytic anemia during hepatitis A infection has not been elucidated completely. Hemolytic anemia could be associated with shortened red cell survival, or it might be autoimmune in nature $[12,15]$. Massive hemolysis has been reported in patients with infection with hepatitis A, B, or E viruses and a concomitant glucose-6phosphate dehydrogenase (G6PD) deficiency [1, 10]. G6PD deficiency and hepatitis A virus infection are common in patients in Mediterranean countries, and the presence of viral hepatitis A and G6PD deficiency in the same patient therefore would be expected.

Two studies done in two different regions of Turkey show that the prevalence of G6PD deficiency is high, reaching up to $10 \%$ in some ethnic populations (the normal range is $3 \%-8 \%$ ) $[2,3]$. The G6PD enzyme catalyzes the oxidation of glucose and maintains glutathione in its reduced form [5]. In patients with a G6PD deficiency, this enzyme is deficient in liver cells as well as in erythrocytes. It has been suggested that this deficit may prevent the repair of hepatocytes damaged by viral hepatitis and, as a result of increased oxidative damage to hepatocytes because of glutathione depletion, may increase liver damage [9]. Patients with infection with acute viral hepatitis $\mathrm{A}$ and a concomitant G6PD deficiency have a statistically significantly prolonged prothrombin time, a higher temperature, and elevated leukocyte counts and mean serum bilirubin levels (including direct bilirubin) [9].

Here, we report two children with hemolytic anemia during the course of hepatitis A infection. Both had a G6PD deficiency and autoimmune antibodies. We discuss the etiology of acute severe hemolysis and describe our management of intravascular hemolysis, severe hyperbilirubinemia, hepatic encephalopathy, and acute renal failure in these patients.

\section{Patient 1}

A 10-year-old previously healthy boy with a 4-day history of jaundice, fatigue, vomiting, and abdominal pain that radiated to his back was transferred to our hospital. A diagnosis of hepatitis A had been made in another hospital. This patient had no history of liver disease or a hereditary blood disease, exposure to a toxic agent, recent treatment with medication, or recent ingestion of fava. On physical examination, because of severe abdominal pain, the patient was in the chest-knee position. He appeared weak, but was conscious. He was severely jaundiced. Tenderness to palpation with rebound in the right upper quadrant and epigastrium was noted, as was hepatomegaly with a liver span of $2 \mathrm{~cm}$. The spleen was $2 \mathrm{~cm}$ below the subcostal margins at the midclavicular line.
The results of laboratory testing on admission were as follows (expected ranges in parenthesis): hemoglobin $(\mathrm{Hb})$, $8.5 \mathrm{~g} / \mathrm{dl}$ (12-15); white blood cell count (WBC), 26.1× $10^{9} / 1\left(4.5-11 \times 10^{9} / 1\right)$; mean corpuscular hemoglobin, $31.7 \mathrm{pg}$ (25-34); mean corpuscular volume, $90.7 \mathrm{fl}$ (75-95); platelet count, $329 \times 10^{9} / 1\left(150-400 \times 10^{9} / 1\right)$; blood urea nitrogen (BUN), $33 \mathrm{mg} / \mathrm{dl}$ (6-21); creatinine, $0.75 \mathrm{mg} / \mathrm{dl}(0.5-1)$; uric acid, $9.9 \mathrm{mg} / \mathrm{dl}$ (2-5.8); aspartate aminotransferase, 8,943 U/ 1 (0-40); alanine aminotransferase, 6,880 U/1 (0-41); gamma glutamyl transferase, $156 \mathrm{U} / 1$ (18-61); alkaline phosphatase, $291 \mathrm{U} / 1$ (100-250); total bilirubin, $52.41 \mathrm{mg} / \mathrm{dl}(0-1.2)$; direct bilirubin, $32.12 \mathrm{mg} / \mathrm{dl}(0-0.3)$; ammonia, $70 \mu \mathrm{mol} / 1$ (14.7$55.3)$; lactate, $5.4 \mathrm{mmol} / 1$ (0.7-2.1); prothrombin time, $18.9 \mathrm{~s}$ (11-15); international normalized ratio, 1.56 (1-1.2); fibrinogen, $207 \mathrm{mg} / \mathrm{dl}$ (200-400). A peripheral blood smear showed $48 \%$ neutrophils, $24 \%$ metamyelocytes, $6 \%$ myelocytes, 19\% lymphocytes, and 3\% monocytes. Seven percent of normoblasts with fragmented erythrocytes and diffuse spherocytes also were seen (Table 1).

Initially, the patient was rehydrated and received supportive care that included maintaining the fluid-electrolyte balance. He was treated with intravenous cefotaxime because of his high fever and leukocytosis; vitamin $\mathrm{K}(5 \mathrm{mg})$ was administered intravenously. Eight hours later, his overall condition had deteriorated, and his hemoglobin level decreased to $5.1 \mathrm{~g} / \mathrm{dl}$. His urine was dark brown. His reticulocyte count was $6.75 \%$ (normal range, $0.5 \%-1.5 \%$ ), and his haptoglobulin level was $4 \mathrm{mg} / \mathrm{dl}$ (normal range, $30-300 \mathrm{mg} / \mathrm{dl}$ ). The results of direct and indirect Coombs' tests and erythrocyte osmotic fragility tests were negative, and the results of hemoglobin electrophoresis were within the normal range. His serum iron level was $224 \mu \mathrm{g} / \mathrm{dl}$ (normal range, 60-170 $\mu \mathrm{g} / \mathrm{dl}$ ), his serum iron-binding capacity was $2 \mu \mathrm{g} / \mathrm{dl}$ (normal range, 130 $350 \mu \mathrm{g} / \mathrm{dl}$ ), and his ferritin level was 1,274 ng/dl (normal range, $20-200 \mathrm{ng} / \mathrm{dl}$ ). His lactate dehydrogenase level was $5979 \mathrm{U} / 1$ (normal range, 180-430 U/1). The results of a urine analysis showed hemoglobinuria without erythrocytes. The results of an assay for G6PD showed a low level of enzymatic activity $(1.34 \mathrm{U} / \mathrm{g} \mathrm{Hb}$; normal range, 4.6-13.5 U/g Hb). G6PD activity was determined by the kinetic (ultraviolet) method (Sigma Diagnostic, Germany). Hepatitis B, C, D, and E viruses, Cytomegalovirus, Epstein-Barr virus, human immunodeficiency virus, parvovirus B 19, herpes simplex virus types 1 and 2, toxoplasmosis, and rubella infection were ruled out by the results of serologic assays. The results of testing for serum hepatitis A virus immunoglobulin $\mathrm{G}$ and immunoglobulin $\mathrm{M}$ antibodies were positive. The patient was diagnosed as having viral hepatitis $\mathrm{A}$, and hemolytic anemia. The results of testing for antinuclear antibody (ANA) (1/40), smooth muscle antibody (SMA) (1/40), and antidoublestranded deoxyribonucleic acid (antidsDNA; $75.3 \mathrm{U} / \mathrm{ml}$ (normal range, $0-25 \mathrm{U} / \mathrm{ml}$ )) were positive. The patient required repeated blood transfusions because of his progressive anemia. 
Table 1 Laboratory findings of patients

SMA: smooth muscle antibodies ANA: antinuclear antibodies antids DNA: Antidoublestranded deoxyribonucleic acid

\begin{tabular}{|c|c|c|c|c|c|}
\hline \multirow[t]{2}{*}{ Variable } & \multicolumn{2}{|l|}{ Patient 1} & \multicolumn{2}{|l|}{ Patient 2} & \multirow[t]{2}{*}{$\mathrm{nl}$ values } \\
\hline & Admission & $8 \mathrm{~h}$ later & Admission & $\begin{array}{l}12 \\
\mathrm{~h} \text { later }\end{array}$ & \\
\hline $\mathrm{Hb}, \mathrm{g} / \mathrm{dl}$ & 8.5 & 5.1 & 9.8 & 6.1 & $12-15$ \\
\hline $\mathrm{WBC}, \times 10^{9} / 1$ & 26.1 & 30 & 23.9 & & $4.5-11$ \\
\hline Reticulocyte, $\%$ & & 6.75 & & 18.9 & $0.5 \sim 1.5$ \\
\hline $\mathrm{LDH}, \mathrm{U} / 1$ & & 5979 & & 1570 & $180-430$ \\
\hline Haptoglobulin, mg/dl & & 4 & & 25 & \\
\hline G6PD, U/g Hb & & 1.34 & & 1.8 & $4.6-13.5$ \\
\hline BUN, mg/dl & 33 & 51 & 46 & & $6.0-21$ \\
\hline Creat, mg/dl & 0.75 & 1.45 & 1.6 & & \\
\hline Uric acid, $\mathrm{mg} / \mathrm{dl}$ & 9.9 & 11 & 10.8 & & $2.0-5.8$ \\
\hline Total bilirubin, $\mathrm{mg} / \mathrm{dl}$ & 52.41 & 55.9 & 48 & & $0.0-1.2$ \\
\hline Direct bilirubin, $\mathrm{mg} / \mathrm{dl}$ & 32.12 & 32.17 & 31 & & $0.0-0.3$ \\
\hline Direct Coombs' test & & Negative & & Negative & Negative \\
\hline Autoantibodies & ANA, SMA, antidsDNA & & SMA & & Absent \\
\hline
\end{tabular}

Although he was adequately hydrated and alkalized, his serum BUN and creatinine levels increased to $51 \mathrm{mg} / \mathrm{dl}$ and $1.45 \mathrm{mg} / \mathrm{dl}$, respectively. His urine output decreased to less than $500 \mathrm{ml} /$ day. To prevent renal damage, plasmapheresis with fresh frozen plasma was performed three times for the clearance of bilirubin and plasma hemoglobin. The hyperbilirubinemia responded to plasmapheresis. However, acute tubular necrosis complicated the clinical course because several sessions of hemodialysis were required. The patient was discharged from the hospital 1 month after his admission, at which time the values of his liver and kidney functions were almost within their respective normal ranges. Two months later, the results of tests for ANA, SMA, and antidsDNA were negative. His hemoglobin level was normal.

\section{Patient 2}

A 5-year-old girl with encephalopathy, vomiting, icterus, and fever for 3 days was admitted to our hospital for treatment. She had taken no medication and had not ingested fava. Her brother had been diagnosed as having acute hepatitis A infection. At the time of her physical examination, she was stuporous and her temperature was $38^{\circ} \mathrm{C}$. Her sclerae were icteric, her liver was palpable $1 \mathrm{~cm}$ below the subcostal margins at the midclavicular line, and her spleen was not palpable. The results of laboratory studies performed at the patient's admission were as follows (expected ranges in parenthesis): $\mathrm{Hb}, 9.8 \mathrm{~g} / \mathrm{dl}(12-15)$; WBC, $23.9 \times 10^{9} / 1\left(4.5-11 \times 10^{9} / 1\right)$; mean corpuscular hemoglobin, 26 pg (25-34); mean corpuscular volume, $81 \mathrm{fL}$ (75-95); platelet count, $751 \times 10^{9} / 1\left(150-400 \times 10^{9} / 1\right.$; glucose, $111 \mathrm{mg} / \mathrm{dl}$ (60-100); aspartate aminotransferase, 1,157 U/1
(0-40); alanine aminotransferase, 1,601 U/1 (0-41); alkaline phosphatase, 256 U/1 (100-250); gamma glutamyl transferase, $54 \mathrm{U} / 1$ (18-61); total bilirubin, $48 \mathrm{mg} / \mathrm{dl}(0-1.2)$ with a direct fraction of $31 \mathrm{mg} / \mathrm{dl}(0-0.3) ; \mathrm{BUN}, 46 \mathrm{mg} / \mathrm{dl}(6-21)$; creatinine, $1.6 \mathrm{mg} / \mathrm{dl}(0.5-1)$; uric acid, $10.7 \mathrm{mg} / \mathrm{dl}(2-5.8)$; ammonia, $256 \mu \mathrm{mol} / \mathrm{l}$ (14.7-55.3); lactate dehydrogenase, 1,570 U/1 (180-430); prothrombin time, $18.5 \mathrm{~s}$ (11-15); international normalized ratio, 1.59. The results of tests for serum levels of copper, ceruloplasmin, alfa-1 antitrypsin, ANA, and antidsDNA were negative, and the test result for SMA was positive (1/80). The results of serologic testing for hepatitis B, C, D, and E viruses, Toxoplasma gondii, rubella, Epstein-Barr virus, Cytomegalovirus, herpes simplex virus types 1 and 2, and human immunodeficiency virus were all negative, but IgM antibody against hepatitis A was positive (Table 1).

Therapy with a third-generation cephalosporin (cefotaxime), lactulose, ranitidine, and oral ampicillin was begun according to our protocol for treating hepatic encephalopathy, and vitamin $\mathrm{K}$ (5 mg) was administered intravenously. Plasmapheresis with fresh frozen plasma was performed in two sessions that were $12 \mathrm{~h}$ apart. Twelve hours after her admission to the hospital, the patient's $\mathrm{Hb}$ and Hct levels decreased to $6.1 \mathrm{~g} / \mathrm{dl}$ and $19 \%$, respectively. She required a red cell transfusion because of progressive anemia. A peripheral blood smear showed 79\% neutrophils, target cells, anisocytosis, and poikilocytosis. Her reticulocyte count was $18.9 \%$, her haptoglobin level was $25 \mathrm{mg} / \mathrm{dl}$, and the results of a direct Coombs' test were negative. Hemoglobin electrophoresis revealed 99.1\% hemoglobin A1 and $0.9 \%$ hemoglobin A2. A spot urine examination showed two positive results (for hemoglobinuria and bilirubinuria). Her G6PD level showed a low level of 
enzymatic activity $(1.8 \mathrm{U} / \mathrm{g} \mathrm{Hb}$; normal range, $4.6-13.5 \mathrm{U} / \mathrm{g}$ $\mathrm{Hb}$ ). Two sessions of plasmapheresis were performed. She was adequately hydrated, and her urine output remained within normal limits. Her encephalopathy resolved, and her bilirubin, BUN, and creatinine levels returned to values within the normal range. The duration of her hospitalization was 11 days. Six months after her discharge from the hospital, her G6PD activity was re-evaluated, and the result of the assay was below the normal range. Her SMA test result was negative, and her hemoglobin level was within the normal range.

\section{Discussion}

Infection with hepatitis A generally is believed to be selflimited; however, it can produce effects that range from a lack of symptoms to death from fulminant hepatitis [8]. Hemolytic anemia is an extrahepatic manifestation of viral hepatitis, including hepatitis A. Although the results of direct Coombs' tests were negative, both patients reported here had the presence of autoimmune antibodies such as ANA, SMA, and antidsDNA. In genetically predisposed individuals, infections could act as environmental triggers inducing or promoting autoimmune disease [4]. It has been suggested that acute hepatitis A virus infection induces autoimmune hemolytic anemia [15]. Infection with hepatitis A virus might have played a role in the acute hemolysis in our patients. Nevertheless, during follow-up, no hemolytic anemia was detected, and the autoimmune antibodies disappeared. Except for plasmapheresis, our patients received no specific treatment for autoimmune hemolytic anemia. The proper role of plasmapheresis when treating autoimmune hemolytic anemia remains uncertain [14]. Some authors believe that plasmapheresis helps stabilize patients with fulminant hemolysis or improves responsiveness to transfusions. Available clinical data are limited to case reports that do not always show improvement. For this reason, we could not totally relate our patients' acute hemolysis to postinfectious autoimmune hemolytic anemia. Berlin and associates [4] reported that in nonautoimmune individuals with various infections, elevated titers of autoantibodies could be detected by molecular mimicry of microbial peptides similar to self-tissues. The transient nature of the autoantibodies in our patients could be explained by this.

Our patients had low levels of G6PD. Administration of vitamin $\mathrm{K}$, which is known to cause hemolysis in patients with a G6PD deficiency, could have precipitated the hemolysis. Hemolytic episodes are associated with acute and chronic hepatitis; these episodes occur in patients with viral hepatitis A and a G6PD deficiency [5, 6, 9]. Hepatitis A also is prevalent in the Mediterranean area, and the concomitant occurrence of those two relatively common conditions (hepatitis A and G6PD deficiency) in the same patient would therefore be expected. Chau and colleagues [7] retrospectively studied 434 patients with acute hepatitis and found that the overall incidence of acute hemolysis was $4 \%(17 / 434)$. In that series, $53 \%$ of the patients with hemolysis had a G6PD deficiency.

The G6PD deficiency is an X-linked disorder. Most heterozygous women and girls do not have clinical hemolysis after exposure to oxidant stress. Rarely, the majority of the erythrocytes are G6PD deficient in heterozygous females, because of random inactivation of the normal $\mathrm{X}$ chromosome [5]. The milder clinical evolution seen in patient 2 could have been because the patient was a heterozygous girl. She did not require hemodialysis. Although she had encephalopathy on admission, she became conscious after two sessions of plasmapheresis. Her encephalopathy possibly was related to a high serum ammonia level.

Because G6PD is the only way to generate a reduced form of nicotinamide-adenine dinucleotide phosphate, a substance that maintains the reduced form of glutathione (which protects against oxidative damage) in cells, hemolysis may develop in G6PD-deficient patients with viral hepatitis A. Abnormally low levels of glutathione, which revert to normal levels after a patient's recovery, have been identified during hepatitis infection [7]. The level of glutathione, which is already low in patients who are G6PD deficient, decreases further in people with infections, including hepatitis $[5,11]$.

Kattamis and Tjortjatou [11] observed minor evidence of hemolysis in $23 \%$ of patients with viral hepatitis who were not G6PD deficient. However, they noted mild, moderate, or severe hemolysis in $87 \%$ of G6PD-deficient persons. They reported that their patients with acute viral hepatitis with G6PD deficiency with or without hemolysis had higher bilirubin values than did patients with viral hepatitis without G6PD deficiency. Hemolysis was not always associated with hyperbilirubinemia in their G6PD-deficient patients. These investigators [11] suggested that a hepatic factor (perhaps direct hepatic damage) rather than hemolysis might be responsible for severe hyperbilirubinemia in patients with a G6PD deficiency.

Similarly, Gotsman and Muszkat [9] reported that patients with hepatitis A and a G6PD deficiency had a more severe clinical presentation characterized by neurologic deterioration, severe hemolysis, and a longer hospital stay than did patients with hepatitis A without a G6PD deficiency. These authors studied 200 patients with hepatitis A and found that $18(9 \%)$ were G6PD deficient, and that hemolysis occurred in $44 \%$ of the patients with a G6PD deficiency. When compared with patients without a G6PD deficiency who had the same infection, the G6PD-deficient 
patients had a higher-grade fever, leukocytosis, and higher bilirubin level. The high bilirubin levels in patients with G6PD deficiency and hepatitis A could not be entirely explained by hemolysis, because both total and direct bilirubin levels were statistically significantly higher in all patients with G6PD deficiency, including those without hemolysis. In patients with a G6PD deficiency, the prothrombin time was statistically significantly longer than that it was in controls. These authors suggest that the G6PD enzyme deficiency might increase the severity of liver damage.

The G6PD deficiency may have deleterious effects on bilirubin metabolism. In a study by Morrow and colleagues [13], severe (and primarily) direct hyperbilirubinemia in patients with chronic hepatitis and a G6PD deficiency was attributed to the direct disruption of bilirubin metabolism or to direct damage to the liver. Hepatocellular damage and cholestasis were revealed in the results of liver biopsy in those patients.

In our two patients, clinical and laboratory findings (i.e., neurologic deterioration, severe hemolysis, high temperature, high leukocyte count, and elevated serum bilirubin level) were consistent with the data in previous reports $[9$, 11,13 , and the direct fraction of bilirubin was higher than the indirect fraction. We suggest that intravascular hemolysis in the presence of liver disease may cause severe hyperbilirubinemia, as the patients described in this report demonstrate.

Although acute tubular necrosis leading to acute renal failure and death has been reported in patients with acute viral hepatitis A $[6,9,10]$, significant renal dysfunction in patients with that type of hepatitis is rare. Because of the lack of controlled trials, the role of plasmapheresis in preventing renal dysfunction has not been well established. Although the hyperbilirubinemia in our first patient responded to plasmapheresis, acute renal failure could not be prevented, and hemodialysis was required.

In conclusion, we suggest that all patients with acute viral hepatitis A and marked hyperbilirubinemia be carefully observed for hemolysis and subsequent renal dysfunction. Prophylactic measures against acute renal failure, such as ensuring the patient's high urinary output, correcting fluid and electrolyte imbalances, and avoiding treatment with nephrotoxic drugs, should be started early. Acute hepatitis A associated with a G6PD deficiency should be considered in the differential diagnosis of patients with acute viral hepatitis and evidence of hemolysis. When hemolytic anemia may be present, vitamin $\mathrm{K}$ administration (which precipitates further hemolysis) should be postponed until a G6PD deficiency has been ruled out. We suggest that G6PD-deficient persons be considered for the hepatitis A vaccine. Genetic screening for the G6PD phenotype should be done to prevent such hemolytic episodes among G6PD-deficient patients, particularly those who are of an ethnic population in which this trait is reportedly more prevalent. In addition to its other benefits, universal vaccination against the hepatitis $\mathrm{A}$ virus is the most effective strategy for preventing hepatitis-A-associated hemolytic complications.

\section{References}

1. Abid S, Khan AH (2002) Severe hemolysis and renal failure in glucose-6-phosphate dehydrogenase deficient patients with hepatitis E. Am J Gastroenterol 97:1544-1547

2. Akoğlu T, Ozer FL, Ciğ S, Kumi M, Erdoğan A, Anil H (1981) Glucose-6-phosphate dehydrogenase deficiency in Cukurova Province, Turkey. Int J Epidemiol 10:27-29

3. Aksoy M, Kutlar A, Kutlar F, Dinçol G, Erdem S, Baştesbihçi S (1985) Survey on haemoglobin variants, beta thalassaemia, glucose-6-phosphate dehydrogenase deficiency, and haptoglobin types in Turks from western Thrace. J Med Genet 22:288-290

4. Berlin T, Zandman-Goddard G, Blank M, Matthias T, Pfeiffer S, Weis I, Toubi E, Singh S, Asherson R, Fraser A, Gilburd B, Sapir T, Levy Y, Lukac J, Rozman B, Kveder T, Shoenfeld Y (2007) Autoantibodies in nonautoimmune individuals during infections. Ann N Y Acad Sci 1108:584-593

5. Beutler E (1994) G6PD deficiency. Blood 84:3613-3636

6. Chan TK, Todd D (1975) Haemolysis complicating viral hepatitis in patients with glucose-6-phosphate dehydrogenase deficiency. Br Med J 1:131-133

7. Chau TN, Lai ST, Lai JY, Yuen H (1997) Haemolysis complicating acute viral hepatitis in patients with normal or deficient glucose-6phosphate dehydrogenase activity. Scand J Infect Dis 29:551-553

8. Cuthbert JA (2001) Hepatitis A: old and new. Clin Microbiol Rev $14: 38-58$

9. Gotsman I, Muszkat M (2001) Glucose-6-phosphate dehydrogenase deficiency is associated with increased initial clinical severity of acute viral hepatitis A. J Gastroenterol Hepatol $16: 1239-1243$

10. Huo TI, Wu JC, Chiu CF, Lee SD (1996) Severe hyperbilirubinemia due to acute hepatitis A superimposed on a chronic hepatitis B carrier with glucose-6-phosphate dehydrogenase deficiency. Am J Gastroenterol 91:158-159

11. Kattamis CA, Tjortjatou F (1970) The hemolytic process of viral hepatitis in children with normal or deficient glucose-6-phosphate dehydrogenase activity. J Pediatr 77:422-430

12. Lyons DJ, Gilvarry JM, Fielding JF (1990) Severe haemolysis associated with hepatitis A and normal glucose-6-phosphate dehydrogenase status. Gut 31:838-839

13. Morrow RH Jr, Smetana HF, Sai FT, Edgcomb JH (1968) Unusual features of viral hepatitis in Accra, Ghana. Ann Intern Med 68:1250-1264

14. Szczepiorkowski ZM, Bandarenko N, Kim HC, Linenberger ML, Marques MB, Sarode R, Schwartz J, Shaz BH, Weinstein R, Wirk A, Winters JL (2007) Guidelines on the use of therapeutic apheresis in clinical practice: evidence-based approach from the Apheresis Applications Committee of the American Society for Apheresis. J Clin Apher 22:106-175

15. Tibble JA, Ireland A, Duncan JR (1997) Acute autoimmune haemolytic anaemia secondary to hepatitis A infection. Clin Lab Haematol 19:73-75 